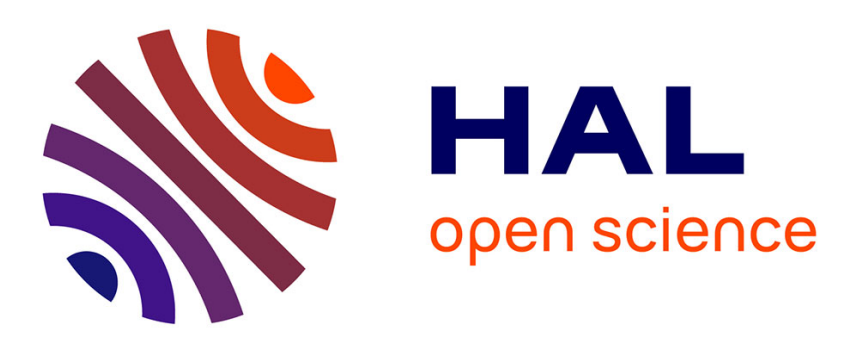

\title{
Performance assessment and definition of improvement paths for microfinance institutions: An application to a network of village banks in Cameroon
}

Isabelle Piot-Lepetit, Joseph Nzongang

\section{- To cite this version:}

Isabelle Piot-Lepetit, Joseph Nzongang. Performance assessment and definition of improvement paths for microfinance institutions: An application to a network of village banks in Cameroon. International Transactions in Operational Research, 2019, 26 (4), pp.1188-1210. 10.1111/itor.12572 hal-02619461

\section{HAL Id: hal-02619461 \\ https://hal.inrae.fr/hal-02619461}

Submitted on 25 May 2020

HAL is a multi-disciplinary open access archive for the deposit and dissemination of scientific research documents, whether they are published or not. The documents may come from teaching and research institutions in France or abroad, or from public or private research centers.
L'archive ouverte pluridisciplinaire $\mathbf{H A L}$, est destinée au dépôt et à la diffusion de documents scientifiques de niveau recherche, publiés ou non, émanant des établissements d'enseignement et de recherche français ou étrangers, des laboratoires publics ou privés. 


\title{
Performance assessment and definition of improvement paths for microfinance institutions: An application to a network of village banks in Cameroon
}

\author{
Isabelle Piot-Lepetit ${ }^{\mathrm{a}}$ and Joseph Nzongang ${ }^{\mathrm{b}}$ \\ ${ }^{a}$ MOISA, INRA, Economics and Management Division, Univ Montpellier, Montpellier, France, \\ ${ }^{\mathrm{b}}$ Faculty of Economics and Management, University of Dschang, Cameroon \\ E-mail: isabelle.piot-lepetit@inra.fr [Piot-Lepetit] ; jonzongang@gmail.com [Nzongang]
}

\author{
Published in International Transactions in Operational Research \\ http://dx.doi.org/10.1111/itor.12572
}

\begin{abstract}
The objective of this paper is an assessment of the financial and social performance of a network of village banks in Cameroon and the provision of data-driven guidance to managers helping them in their decision making process. An analysis framework in three stages is developed. First, a Data Envelopment Analysis (DEA) analysis is implemented for measuring efficiency, identifying best-practices, and setting goals to less efficient MFIs. Then, a DEA operating frontiers (DEA-OF) model is designed to identify improvement paths setting short-term goals towards their long-term DEA objective and providing effective and time dependent guidance to managers in their efficiency improvement process. Finally, DEA and DEA-OF results are translated into financial and non-financial indicators daily used by managers through three different and interrelated scorecards. Besides, results of this third stage are used for identifying village banks ready for the new phase of development of the network aiming to funding community projects.
\end{abstract}

Keywords: microfinance; data envelopment analysis; DEA operating frontiers; financial and social efficiency; OR for development 


\section{Introduction}

Cameroon is a country with vast natural resources and a population of 23 million people. It is also culturally and geographically very diverse, with nearly 250 different linguistic groups, two official languages (English and French), and all major climates and vegetation of the African continent on its territory. This country is currently considered as a lower middle-income country by the World Bank (2016) with social indicators and levels of poverty that are below those for comparator countries. However, the government of Cameroon aims to achieve the state of higher-middle income country by 2035. The World Bank considers that there exists a huge potential for economic growth and poverty reduction in Cameroon. Indeed, over the last decade, the country has been characterized by a positive economic growth from $4.6 \%$ in 2012 to $5.9 \%$ in 2015, spurred by large public investments in infrastructure. But, to attain the higher middle-income status by 2035, growth needs to accelerate further; requiring a substantial increase in the level of investments from $20 \%$ to $32 \%$ of GDP (World Bank, 2016). As the public sector alone cannot bring this about, much more private investment is necessary as well as improvements in the business environment (Piot-Lepetit, 2017)

However, despite economic growth, national poverty has remained almost unchanged. While Cameroon is urbanizing rapidly, poverty remains a rural phenomenon and is increasingly concentrated in Northern Cameroon. In 2014, poverty was at 38\% with more than $90 \%$ in rural areas and $57 \%$ of all poor people located in the north of the country. Indeed, poverty decreased from 40\% in 2001 to 38\% in 2014, but with a declined in urban areas from 18\% in 2001 to $9 \%$ in 2014 and an increase in rural areas from 52\% in 2001 to $57 \%$ in 2014. Besides, the rapid increase in poverty in Northern Cameroon occurred before Boko Haram activity. But, poverty estimates for the Northern region should be considered as lower bounds, since the consequence of the increased influence of refugees, internally displaced persons, and the closure of markets, roads, and frontiers has not been taken into account by national statistics (World Bank, 2016). Thus, the Millennium development goal of $25 \%$ of poverty by 2015 is not achieved (Miamo Wendji, 2017)

Microfinance is an activity that supplies financial services to low-income population, which normally does not have access to the conventional banking system. Microfinance services mainly include loans and savings, but some microfinance institutions also provide micro-insurance as well as other financial services such as remittances or mobile telephony, among others. Usually the poor have no access to loans from the conventional banking system, because they cannot put up acceptable collateral and/or because costs of screening, monitoring the activities of the poor, and enforcing their contracts are too high for banks to make lending to this group profitable (Hermes and Lensink, 2007). Lack of access to credit is generally seen as one of the main reasons why many people in developing countries remain poor. For Pr. Yunnus, founder of the Grameen Bank and the 2006 Nobel Peace Prize, the poor have skills that remain un- or under-utilized, mainly because existing institutions or policies do not offer them the support they need (Seelos and Mair, 2005). 
In Cameroon, the Mutelles Communautaires de Croissance (or $\mathrm{MC}^{2}$ ) network is a communitybased development model conceived to fight against poverty by mobilizing savings and resources within rural communities. Founded in 1992, this network of village banks provides microfinance services in rural Cameroon with the objective of improving living conditions of targeted populations and promoting agriculture and rural development. Nowadays, there exist more than 70 micro-banks within this network (Piot-Lepetit and Nzongang, 2014). Each entity provides structures that people trust and help them escape the poverty trap and gain control over their lives. Designed on local needs, these non-profit social enterprises have a mission of providing financial services that cater directly to basic human needs remaining unsatisfied by more conventional institutions in both the economic and social domain (Seelos and Mair, 2005). Thus, these microfinance institutions (MFIs) have a dual nature and face a 'double bottom line' (Yaron, 1994): a financial bottom-line that is to achieve financial sustainability and selfsufficiency and a social bottom-line that is to financially support individual business projects. A successful management of MFIs is seen as a simultaneous expansion of both components without tradeoffs between the objectives of financial sustainability and outreach to the poor (Morduch, 2000).

The $\mathrm{MC}^{2}$ network has grown in three phases that include: (1) sensitizing the poor population to the concept of village bank, (2) mobilizing resources, especially through micro-savings, and (3) financing individual income-generating activities. In 2010, the fourth phase of development of this network, the promotion of community economic projects, has been launched. This new phase is expected to boost development projects with an objective of job creation supported by communities where micro-banks are deployed. In order to invest this new challenge, an evaluation of the performance and sustainability of the $\mathrm{MC}^{2}$ network and its village banks was thought as a step helping identify strengths and weaknesses before starting new projects at a meso- and collective level; representing an important change in their current micro- and individual level. Besides, identifying entities ready for the $4^{\text {th }}$ phase of development of the network relying on data-based information was considered as more pertaining than just using experience and intuition. The study was consequently implemented in two steps. The first one, described in Piot-Lepetit and Nzongang (2014), aimed at providing a comprehensive evaluation of the financial and social performance of these village banks by decomposing their microfinance activities into processes and sub-processes. The second step, presented hereafter, focuses on describing meaningful and usable course of actions to support decision making, planned in time and based on data-driven information.

To gain a holistic view of the network performance and to provide operational recommendations to managers of village banks helping them become more efficient, Piot-Lepetit and Nzongang (2014) used the Data Envelopment Analysis (DEA) approach for evaluating the financial and social performance of the $\mathrm{MC}^{2}$ network and its micro-banks in 2009. DEA is an OR technique based on linear programming models that provides managers with a data-driven mechanism by which to assess and manage the efficiency of their units, avoiding them to just work on intuition and instinct concerning the management of the organization's performance but also to rely on rigorous quantitative analyses. DEA, 
initially developed by Charnes et al (1978), is a nonparametric method aiming at measuring the efficiency of decision-making units (DMUs) by simultaneously considering the multiple resources used (the inputs) to generate multiple goods and services (the outputs). Besides, DEA requires no assumption on the functional relationships between inputs and outputs and allows an efficiency evaluation of individual DMUs through the choice of most favorable optimal weights (Xia et al., 2017). The main advantage of DEA is the provision of efficiency scores that can be used as specific goals on which managers can focus to improve their performance within a multiple-input and multiple-output context as well as the identification of best-performers that are not always visible through commonly used management methodology (Sherman and Zhu, 2013) and can be used as role models in the process of efficiency improvement. DEA has already been applied in numerous domains such as accounting (Hsiao et al., 2017), agriculture (Chemak et al., 2010; Da Silva e Souza and Gonçalves Gomes, 2015; Watto and Mugera, 2016), airlines (Gomes Junior et al., 2016), education (Kounetas et al., 2011; Tran and Villano, 2015), hardware computers (Sahoo et al., 2012), hospitals (Marques and Carvalho, 2013; Ghiyasi, 2016), power plants (Yadav et al., 2014; Calabria et al., 2016), soccer players (Santin, 2014), and banking and finance (Basso and Funari, 2014; Chiu et al., 2014; Shyu et al., 2015; Moreno and Lozano, 2016; Chen et al., 2017), among others.

Thus, using existing available data and the organization's priorities, Piot-Lepetit and Nzongang (2014) evaluated the financial and social performance of the $\mathrm{MC}^{2}$ network in its multi-components so as to enable managers to better monitor and manage their operations processes. Especially, recommendations were made to help village banks' managers to become more efficient and to work without trade-offs in the provision of their financial and social services to poor people. This latter point is especially important because entities of the network are independent actors sharing the same name, and thus maintaining alignment with initial missions is of the utmost importance for top managers. Besides, to facilitate the integration of this data-driven information and minimizing the disruption effect brought about by this new decision-making process to which top and local managers of the network are unaccustomed to (Luoma, 2016), DEA results were transmitted to managers using dashboards specifically designed by international regulatory agencies for microfinance institutions (CGAP, 2003; Microrate, 2003) and a social scorecard developed by Woller (2006). Even though insights provided by this first step of our study were highly positively received by managers of the network, two main extensions were thought as necessary in order to put recommendations into action: (i) the provision of effective guidance to managers planned in time and (ii) the design of smaller and more simple dashboards for communicating new knowledge throughout the network. In addition, (iii) a data-driven support for identifying village banks ready for the fourth phase of development of the $\mathrm{MC}^{2}$ network was asked for by top-managers. The second step of our study focuses on these three points and is the subject of this paper.

To answer the first additional request of the $\mathrm{MC}^{2}$ network, a DEA operating frontiers (DEA-OF) approach has been designed in order to identify the various operating environments under which village 
banks are undertaking their activity and to characterize performance improvement paths as step-by-step movements towards the overall DEA frontier. This extension of the conventional DEA approach allows us to describe the best course of time dependent actions to foster efficiency of current operations, based on available data and the microfinance production process defined in Piot-Lepetit and Nzongang (2014). Regarding the second request, the translation of DEA results is still provided through dashboards based on financial and non-financial indicators daily used by managers to monitor their operations, but using three different and interrelated scorecards. These latter provide effective and reliable guidance to managers at both the top and local levels using either a three-dimensional, six-dimensional, or more detailed format. These new scorecards are linked to each other and were found very useful to provide insights and recommendations regarding the third request concerning the identification of village banks ready for the fourth phase of development of the network.

The paper is organized as follows. First, it provides a brief description of the $\mathrm{MC}^{2}$ network in Cameroon. Then, in the methodological section, the DEA-OF approach as well as the new scorecards provided to managers of the network are introduced. Then, results are presented with a specific attention to the issue of suggesting effective and time dependent guidance to managers and identifying village banks able to grant loans to community projects. Finally, the impacts of the study for the $\mathrm{MC}^{2}$ network and the recommendations to top and local managers of this network as well as to other MFIs worldwide are considered before concluding.

\section{The $\mathrm{MC}^{2}$ network in Cameroon}

The Mutuelles Communautaires de Croissance (or $\mathrm{MC}^{2}$ ) network provides microfinance services through independent village banks. Founded by P.K. Fokam in 1992, the network aims to fight against poverty by mobilizing savings and resources within rural communities in Cameroon. The objective of the $\mathrm{MC}^{2}$ network is the improvement of living conditions of targeted populations and the promotion of agriculture and rural development. Thus, village banks belonging to this network face a double bottomline with an economic objective based on financial sustainability and a social objective of targeting the poor by providing support for the development of micro and small-scale activities in rural Cameroon.

The $\mathrm{MC}^{2}$ structure was first deployed at Baham in the Western region of Cameroon, and then, encouraged by the success, similar initiatives were taken all over the country. The number of members rose sharply over years. In 2007, the network counted 65 rural micro-banks located in the 10 regions of Cameroon and owned by 78,925 members from various communities, along with $24 \%$ of women and $12 \%$ of groups or associations. Financial assistance is provided by the Afriland First Bank, a commercial bank, which plays the role of external auditor and facilitates banking procedures. The non-governmental organization ADAF (Appropriate Development for Africa Foundation) provides support for capability building, staff training, and accounting procedures. ADAF staff make regular visits to the village banks and provide help for specific issues. It is the village population that can take the initiative of creating a 
new $\mathrm{MC}^{2}$. Each mutual fund is an association owned by its members that comprise the whole rural community, including urban people originated from it. The participation of urban people is considered as critically important, particularly as a driving force and a guarantee of credibility during initial phases: motivation of the population and capital investment. Even though, national and international partners provide subventions for the establishment of a new $\mathrm{MC}^{2}$ through $\mathrm{ADAF}$, each $\mathrm{MC}^{2}$ is autonomous and independent from subsidies at the end of the fifth year in activity. For more details on membership procedures, the organization and functioning of the $\mathrm{MC}^{2}$ network, and procedures for granting loans, see Mees and Banda (2001) and Piot-Lepetit and Nzongang (2014, 2017).

Thus, the $\mathrm{MC}^{2}$ network is composed of rural microfinance institutions set up and managed by the population living in or originated from the areas where they are deployed with the technical assistance of a non-governmental organization ADAF and the sponsorship of the African First Bank. The MC ${ }^{2}$ network has grown through three phases that include: (1) sensitizing the poor population to the concept of village bank, (2) mobilizing resources, especially through micro-savings, and (3) financing individual income-generating activities. In 2010, the fourth phase of development of this network has been launched: the promotion of community economic projects. Thus, the $\mathrm{MC}^{2}$ network will now not only financially support the development of micro- and small-scale activities, but also projects aiming to boost development and job creation in rural Cameroon.

\section{Methodology}

For measuring performance in terms of efficiency, characterizing improvement paths for microfinance institutions (MFIs) towards their double bottom-line, providing effective guidance to managers, and identifying village banks ready for the $4^{\text {th }}$ phase of development of the $\mathrm{MC}^{2}$ network, we have developed an analysis framework using synergistically information coming from managers regarding the structure and functioning of their organization and the OR technique called Data Envelopment Analysis or DEA (Charnes et al., 1978; Färe et al., 1985). As explained by Basu (2013), it is the best way to generate a solution to an organization based on available data that could be used by practitioners.

First, a performance assessment is provided using the DEA model describing the overall microfinance activity of the network defined by Piot-Lepetit and Nzongang (2014). Then, improvement paths are obtained by specifying a new DEA approach: the DEA operating frontiers (DEA-OF) model. The latter provides roadmaps describing time dependent actions that can be implemented by managers and easily integrated to their daily activities. Finally, DEA and DEA-OF results are translated into financial and non-financial performance indicators used by managers through 3 different and interrelated scorecards aiming at synthetizing information in various formats and selecting village banks for the $4^{\text {th }}$ phase of development of the $\mathrm{MC}^{2}$ network. 


\subsection{Performance assessment and Data Envelopment Analysis}

Data Envelopment Analysis (DEA) is an OR technique based on linear programming models developed to measure the efficiency of decision-making units (DMUs) that are, in our case study, the village banks of the $\mathrm{MC}^{2}$ network. DEA considers multiple inputs and multiple outputs simultaneously and produces an efficient frontier built upon the set of best performers. These DMUs located on the frontier are the organization leaders. The distance between a DMU and the efficiency frontier provides the DMU with an efficiency score that has to be viewed as its relative efficiency compared to all other DMUs. Thus, DEA divides the sample of DMUs under investigation into two groups: efficient DMUs that receive a score of unity and other DMUs that receive a score below unity and are called inefficient by comparison to the former group. For DMUs in the second group, DEA produces a specific set of efficient units that can be used as role models for efficiency improvement. Depending on its size and scope, each DMU will receive a different set of role models; role models for a small DMU may be different from role models for a large DMU. By moving towards the frontier, a DMU become more efficient.

Assuming there are $J$ DMUs converting $N$ inputs into $M$ outputs, that $\operatorname{DMU}_{j}(j=1, \ldots, J)$ consumes $x_{n j} \geq 0$ of input $n(n=1, \ldots, N)$ to produce $y_{m j} \geq 0$ of output $m(m=1, \ldots, M)$ and that each DMU has at least one positive input and one positive output (Färe et al., 1994), the corresponding output-oriented DEA model is:

$$
\begin{array}{lc}
\max _{\theta^{o}, \lambda^{o}} \theta^{o} & \\
\text { s.t. } \sum_{j=1}^{J} \lambda_{j}^{o} y_{m j} \geq \theta^{o} y_{m o} & m=1, \ldots, M \\
\sum_{j=1}^{J} \lambda_{j}^{o} x_{n j} \leq x_{n o} & n=1, \ldots, N \\
\lambda_{j}^{o} \geq 0 & j=1, \ldots, J \\
\theta^{o} \text { free } &
\end{array}
$$

Model (1) attempts to proportionally increase all outputs of $\mathrm{DMU}_{\mathrm{o}}$ under scrutiny as much as possible, while not changing its current level of inputs. It evaluates the maximum level of outputs that should have been possible to produce based on the resources of $\mathrm{DMU}_{\mathrm{o}}$. For facilitating the reading of results, the efficiency scores can be defined between 0 and unity rather than between 0 and infinity, by applying the following formula: $\delta=1-(\theta-1)$. DMUs for which $\delta=1$ are efficient, while DMUs for which $\delta<1$ are inefficient, meaning that there exists at least one observation in the sample or a combination of observations that would have been able to produce more from the same level of inputs. Thus, the optimal solution $\delta^{o *}$ yields an efficient score for $\mathrm{DMU}_{\mathrm{o}}$, and efficient DMUs that serve as role 
models are identified by the vector of weights: $\lambda^{o *}=\left(\lambda_{1}^{o *}, \ldots, \lambda_{J}^{o *}\right)$. When an efficient DMU is a role model for $\mathrm{DMU}_{\mathrm{o}}$, then the corresponding optimal value in $\lambda^{o *}$ is positive, otherwise the value is zero.

Following Piot-Lepetit and Nzongang (2014), the microfinance activity is described by means of a production approach in which inputs are transformed into loans and savings for evaluating the financial efficiency of village banks as well as into the social outputs most commonly used in the literature that are the breadth of outreach, evaluated by the number of clients, and the depth of outreach, measured by the number of the poor and women served by these micro-banks. Inputs are assets (material capital), equities (financial capital), personnel costs, and other operating expenses. Table 1 provides descriptive statistics of these inputs and outputs for year 2009. The sample contains 52 village banks having more than 5 years in activity ( $75 \%$ of the micro-banks of the $\mathrm{MC}^{2}$ network).

Insert Table 1: Descriptive statistics of DEA inputs and outputs (52 $\mathrm{MC}^{2}$ in 2009)

\subsection{Improvement paths and DEA Operating Frontiers (DEA-OF)}

One of the limitations of the DEA approach introduced in the previous section deals with the fact that it might be quite impossible for an inefficient DMU to achieve its efficiency objective in a single step, especially when the inefficient DMU is far from the efficient frontier. As DEA goals might be unrealistic in the short-term for some inefficient MFIs, we suggest to implement DEA through a step-by-step approach built upon the identification of the operating frontier of each MFI and the characterization of performance improvement paths towards the highest operating frontier that corresponds to the conventional DEA frontier. The approach, suggested herein and called DEA operating frontiers (DEAOF), offers the possibility to define performance improvement paths that direct inefficient DMUs towards their overall objective on a multi-step basis.

In the operations management literature, the theory of performance assumes that as each manager is a rational actor, the observation of his performance is an optimal choice in the current productive environment and stage of development of the productive unit under scrutiny. Indeed, Schmenner and Swink (1998) considered that while the asset frontier results from structural choices made by an organization's investment in plants and equipment, operating frontiers deal with choices made at a plant level by operating management given the structural choices of the organization. As illustrated in Figure 1, observations A, B, C, and D are on different operating frontiers. The observation A, located on the lower operating frontier, can improve its performance by moving upward towards the efficient frontier in one step or in two steps. In the two-step improvement path, the observation A has to first reach the operating frontier of the observation B before going further on. Then, when it is done, the observation $\mathrm{A}$, starting from this new operating frontier, can reach the efficient frontier on which observations $\mathrm{C}$ and 
D are located. Besides, Schmenner and Swink (1998) defined performance improvements as moving towards higher operating frontiers by simultaneously increasing all dimensions of performance; a definition in accordance with the way DEA evaluate efficiency of DMUs. Consequently, a performance improvement path can be identified based on as many operating frontiers are above the operating frontier of the observation under scrutiny. To implement this approach, we have developed the DEA operating frontiers (DEA-OF) model.

Insert Figure 1: The theory of performance frontier (Schmener and Swink, 1998)

DEA-OF starts with clustering DMUs into several operating levels. For this purpose, efficient DMUs defining the conventional DEA efficiency frontier define the first operating frontier (OF1 on Figure 1). Then, they are removed from the sample of observations and the same DEA model is applied to remaining DMUs to form the second operating frontier (OF2 on Figure 1). The subsequent step consists in removing second-level efficient observations from the sample and to apply the DEA model on remaining DMUs. It allows us to identify the third operating frontier (OF3 on Figure 1). The same procedure is applied again until each DMU is located on an operating frontier, i.e., until each DMU receives a score of unity and thus becomes efficient on a specific operating frontier. Afterward, an improvement path consisting in a sequence of goals towards the overall DEA frontier or first operating frontier (OF1) can be characterized; each goal being defined by the distance between the observation and operating frontiers above it (as illustrated in Figure 1). It allows the definition of a gradual action plan or roadmap with achievable and actionable goals for a step-by-step management of performance improvement that may help inefficient DMUs to achieve their long-term DEA objective.

Formally, let's consider the set of efficient DMUs for which $\delta^{*}=1$ as OF1 and the set of all the $J$ DMUs as $S_{J I}$. DMUs on OF1 define the efficiency frontier of the set $S_{J I}$. The second-level efficiency frontier is obtained after the removal of efficient DMUs forming the set OF1 from the set $S_{J I}$ and the implementation of model (1) on the remaining DMUs that constitute the set $S_{J 2}$. The remaining DMUs received a second-level efficiency score $\left(\delta_{O F 2}^{*}\right)$ evaluated relative to OF2, the efficiency frontier of the set $S_{J 2}$. The same process is replicated on the set $\mathrm{S}_{J 3}$ that is formed after the removal of second-level efficient DMUs on OF2 from the set $S_{J 2}$. Using this process repeatedly, several sub-efficiency frontiers or operating frontiers can be obtained. Whereas the traditional DEA approach divides the set of DMUs into two groups as efficient and inefficient, DEA-OF allows a clustering in which each DMU has the possibility to be efficient on its own operating frontier. While the efficient frontier OF1 serves as a longterm objective for all inefficient DMUs, DEA-OF allows the determination of short-term goals and a step-by-step performance improvement path. At each step of a performance improvement path, the DEA-OF model provides the amount by which all outputs can be increased to reduce inefficiency and model roles that can be emulated. 


\subsection{Transferring DEA results by means of 3 different and interrelated scorecards}

In order, to facilitate the implementation of recommendations provided by DEA and DEA-OF, we selected key performance indicators commonly used by managers of the $\mathrm{MC}^{2}$ network as well as by international organizations. It allows an easy translation of our results in a format to which managers are already accustomed to.

Formally, assuming $P I_{i o},(i=1, \ldots, P)$ key performance indicators for $\mathrm{DMU}_{\mathrm{o}}$, optimal values of these indicators are defined as follows:

$$
P I_{i o}^{*}=\sum_{j=1}^{J} \lambda_{j}^{o *} P I_{i j} \quad i=1, \ldots, P
$$

with $\lambda^{o *}$ is estimated by using model (1). Additionally, a potential improvement in those performance indicators for $\mathrm{DMU}_{o}$, i.e. the gap between their current and optimal values $\left(G_{i o}\right)$, is evaluated by:

$$
G_{i o}=P I_{i o}^{*}-P I_{i o} \quad i=1, \ldots, P
$$

The selection of key performance indicators has been first carried out by taking into account data availability in the bookkeeping of the village banks as well as most common practices among managers. Indicators combine a mixture of financial and non-financial performance ratios to give a complete perspective of the missions of these MFIs as recommended by Woller (2006). An agreement on 10 indicators was obtained. However, each manager can add to this minimal set of indicators his own preferred indicators through a dashboard that is easy to update and available on spreadsheet. Then, these 10 indicators (or more, if any) are organized into six items corresponding to the six aspects of outreach defined by Schreiner (2002), namely the worth and cost to clients as well as the breadth, depth, length, and scope of outreach. This scorecard was selected because it provides a precise view of the social benefit of microfinance.

More precisely, the worth to clients is the value clients place on products and services provided by MFIs, i.e., their willingness to pay for loans through the terms of the contract (amount disbursed, term to maturity, and size of installments) and to save (interest rate, minimum balances, and withdrawals). The cost to clients is the sum of price and transaction costs, i.e., direct cash payments for interest and fees, and non-price costs for both non-cash opportunity costs such as time to apply for a loan and indirect cash expenses such as transport, documents, and money needed to use a financial contract. The breadth is the number of clients. The depth is the poverty status of clients. A direct measure is poverty, while indirect proxies are gender (women), location (rural), education (less), ethnicity (minorities), housing (small flimsy houses), and access to public services (lack of access). The length is the timeframe products and services are supplied, i.e., the sustainability of the supply of 
microfinance services. The scope is the number of products and services offered to clients, i.e., the number of different types of financial contracts provided by an MFI (Schreiner, 2002; Woller, 2006).

Finally, the six dimensions of this social scorecard are reduced into three perspectives by putting them in correspondence with the triangle of microfinance (Zeller and Meyer, 2002) that considers as a successful management of MFIs any simultaneous expansion of their financial sustainability, outreach to the poor, and welfare impact. This new scorecard has the main advantage of being very synthetic as well as being recognized by international organizations working on the microfinance sector. As illustrated in Table 2, financial sustainability is concerned with the length and scope of outreach, outreach to the poor deals with the breadth and depth of outreach, and poverty reduction or welfare impact of MFIs corresponds to the worth and cost to clients.

Insert Table 2: Selected indicators for translating DEA and DEA-OF results into scorecards

\section{Results}

\subsection{Performance assessment of the $M C^{2}$ network and improvement paths for less efficient village banks}

Applying the DEA model defined in (1), we found an average efficiency score is 0.899 . Out of the 52 $\mathrm{MC}^{2}$ of our sample, 14 of them are evaluated as efficient and 33 have an efficiency score above 0.9 , which is a relatively good score (see Figure 2 for details). None $\mathrm{MC}^{2}$ have a score below 0.6. Thus, gains resulting from improvements in efficiency correspond to an $10 \%$ increase in all outputs, on average. The $\mathrm{MC}^{2}$ network can be considered as already relatively efficient in the provision of its outputs. It uses at the most its scarce resources. However, a 40\% increase in all outputs (loans, savings, number of clients, and number of the poor and women) is expected for the least efficient observation of the sample. Concretely, it cannot be implemented in a single step without high consequences in the management of this $\mathrm{MC}^{2}$. In order to provide more realistic goals to local managers, we use the DEA operating frontiers (DEA-OF) model, defined in section 3.2, to identify performance improvement paths that are more easily actionable and sound of real importance for less village banks.

Insert Figure 2: Distribution of DEA efficiency scores

An improvement path is a step-by-step expansion of performance towards a long-term objective. Results show that there are five operating frontiers in the sample under consideration. The distribution of MFIs in these different operating levels is illustrated in the first quadrant of Figure 3. DMUs in the first operating level are those identified as efficient with the conventional DEA model, while DMUs in 
other operating levels are composed of $\mathrm{MC}^{2}$ that have become efficient after the removal of previous efficient $\mathrm{MC}^{2}$. Most of the $\mathrm{MC}^{2}$ are located in the first three operating frontiers (78\%), with $27 \%$ on the first operating frontier (OF1) and 33\% on the second operating frontier (OF2). Besides, OF5, which is the lowest operating frontier, contains only $10 \%$ of the sample, i.e., 5 observations. As explicitly shown in the second quadrant of Figure $3, \mathrm{MC}^{2}$ on the fifth operating frontier are among the youngest ones, with an average age of 7 years old. $\mathrm{MC}^{2}$ on the fourth operating frontier are older than those on $\mathrm{OF}_{5}$, with an average age of 9 years old, but younger than those on OF1 to OF3 for which the average age is of 11 years old. Thus, the main difference between operating frontiers lies on the youngest age of village banks on the fifth and fourth operating frontiers. Thus, $\mathrm{MC}^{2}$ that are on the last two operating levels and need longer performance improvement paths are among the most recently established ones.

Insert Figure 3: Distribution and average age of village banks per operating frontier

Table 3 provides performance improvement paths identified by means of the DEA-OF approach. For village banks on the fifth operating frontier (OF5), a movement towards the highest operating frontier (OF1) implies on average an increase in all outputs of $26 \%$. By implementing a step-by-step expansion towards the overall DEA frontier, an improvement of $4 \%$ at the first step, $9 \%$ at the second step, $5 \%$ at the third step, and $8 \%$ at the last step is suggested; providing more realistic and actionable goals to increase all outputs simultaneously. As showed in Table 3, the increase in outputs for each step of improvement paths suggested for all inefficient $\mathrm{MC}^{2}$ is less than $10 \%$; except for $\mathrm{MC}^{2}$ on the fourth operating frontier for which the second step involves an increase in all outputs of $11 \%$.

Insert Table 3: Improvement paths for inefficient $\mathrm{MC}^{2}$

\subsection{Translation of DEA and DEA-OF results into scorecards and selection of village banks for the 4th phase of development of the $M C^{2}$ network}

In order to provide effective guidance to managers of the $\mathrm{MC}^{2}$ network, goals provided by both the DEA and DEA-OF approaches described above have been translated into financial and non-financial indicators. For facilitating the reading of these performance indicators, optimal values for these indicators coming from our DEA and DEA-OF results have been normalized using a 0-10 scale for comparison purposes. Then, each normalized financial and non-financial ratios are averaged in order to provide an overall measure for each of the six aspects of outreach and the three perspectives of the triangle of microfinance (see, Table 2 for details). As a successful management of microfinance is seen 
as a simultaneous expansion of all three or six components of the previous scorecards, no weighting system is applied when averaging normalized indicators.

This communication support of DEA results is illustrated on Figure 4 and shows that the $\mathrm{MC}^{2}$ network as a whole manages the perspectives of the triangle of microfinance of financial sustainability and outreach to the poor in a similar manner but receives a higher evaluation regarding the third component corresponding to the welfare impact. The first two strategic objectives are developed without stressing one or another. It is an important result, since it means that, at the network level, there is not trade-off between the financial and social objective of their activity. The financial and outreach components are slightly below average, while the welfare impact is slightly above average. The latter result comes from the worth to clients, i.e., the value placed on products and services provided by the $\mathrm{MC}^{2}$ network. Members of village banks are willing to save in these micro-banks and to pay for the services provided by these institutions. This can be partly explained by the fact that interest rates provided in the $\mathrm{MC}^{2}$ network are inferior to those of the formal banking system: $10 \%$ to $15 \%$ rather than $22 \%$ on average in conventional banks.

\section{Insert Figure 4: Translation of DEA goals into scorecards}

Scorecards for each DEA operating frontier are illustrated on Figure 5. Regarding $\mathrm{MC}^{2}$ belonging to the first three operating levels, their financial sustainability decreases as they move closer to the highest operating frontier. This result comes from higher write-off and provision expense ratios in comparison to those in other operating groups. For those on OF1 and OF3, it also results from a lower financial self-sufficiency ratio, while for those on OF2 a lower operational efficiency ratio is observed. On the other hand, outreach to the poor increases with efficiency in both its breadth and depth components, i.e., the number of clients and the number of the poor and women. Thus, a mission drift towards more social activities and less involvement in the financial activity is found as village banks become more efficient. Besides, $\mathrm{MC}^{2}$ on the first operating frontier are found to be the most involved in the outreach to the poor. As performance improves, these $\mathrm{MC}^{2}$ are able to reach more poor clients, and as their client portfolio increases, the number of women becomes higher. On the first and second operating frontiers, the number of women is higher than in other operating levels.

Insert Figure 5: Translation of DEA-OF goals scorecards

$\mathrm{MC}^{2}$ on the OF4 and OF5 operating frontiers behave well in regards to the financial and welfare impact perspectives. They both have a high financial self-sufficient (FSS) ratio; those on OF5 having the highest FSS ratio by comparison to other operating levels. As these $\mathrm{MC}^{2}$ are the youngest of the network (see, Figure 3), this result points out that they have concentrated their activity on their financial component rather than on their social one, i.e., they have been more involved in managing 
the robustness of their financial activity than developing their client portfolio. This result is not so surprising, since new $\mathrm{MC}^{2}$ receive the objective of becoming independent of subsidies by the end of the fifth year in activity. Accordingly, the primarily target of an $\mathrm{MC}^{2}$ after its launching is financial viability. Furthermore, $\mathrm{MC}^{2}$ on OF5 have the highest average loan of all efficiency levels; the average amount of the loans served by $\mathrm{MC}^{2}$ in the fifth-level of efficiency is higher than in other operating levels. The average loan size is considered as an indicator of the depth of outreach. The lower the average loan size is, the more committed to poverty reduction MFIs are. This result points out a potential mission drift towards the financial activity for these $\mathrm{MC}^{2}$ due to a too intense focus on their financial sustainability at the beginning of their activity. However, their services are valued by their clients; meaning that their clients are willing to save and borrow money with these institutions.

Besides, the cost to clients on OF5, containing $\mathrm{MC}^{2}$ that are far away from the efficient frontier, is the highest of all operating groups. This cost decreases as efficiency improves.

Thus, our results show that the outreach perspective improves with the performance of village banks, while their financial sustainability tends to decrease; showing a potential mission drift towards their social activity as efficiency within the $\mathrm{MC}^{2}$ network increases. However, the welfare impact is relatively important. Even though the cost to clients for services offered by these micro-banks is high, those services are valuable for their members.

Furthermore, previous results show that $\mathrm{MC}^{2}$ located on OF2 and OF3 are ready for the $4^{\text {th }}$ phase of development of the network, i.e. supporting community projects with an objective of job creation. Indeed, they are in balance with regard to the three objectives of the triangle of microfinance that are financial sustainability, outreach to the poor, and welfare impacts, as illustrated in the first quadrant of Figure 5. As they face no trade-off between the main three dimensions of their microfinance activity, they are considered as candidates for the new phase of development. Regarding $\mathrm{MC}^{2}$ located on OF4 and OF5 operating frontiers, they are still in the first stages of development of their activity. Their main objective is currently to develop their portfolio of members, and especially of poor ones. Thus, our recommendation regarding $\mathrm{MC}^{2}$ on $\mathrm{OF} 4$ and $\mathrm{OF} 5$ is to develop efficiently their activity following directions provided to them by DEA-OF results until they achieve a balance in the three perspectives of the triangle of microfinance. Concerning $\mathrm{MC}^{2}$ on OF1, the trade-off between their financial and social activity towards the latter one was very surprising and unexpected. However, after deeper investigations, the explanation of this situation lies on the fact that village banks on OF1 have already involved themselves into community projects. Thus, our recommendation for the most efficient $\mathrm{MC}^{2}$ is the provision of specific advice on the management of these new projects that involve larger loans as well as a different financing process that does not yet belongs to the set of routine decision making processes of the network. 


\section{Recommendations, impacts and perspectives}

\subsection{Recommendations for implementation in practice}

With the delivery of our results, a set of recommendations has been put forward in order to embed our data-driven solution in routine practices of the network, especially regarding the monitoring and management of performance. Even though developments presented in this paper aim to increase efficiency at the network level by reducing the cognitive effort required to perform decision making tasks, it is also necessary to define a structure of implementation that minimizes resistance among members of the network. Resistance can be mitigated by minimizing the disruption the analytical solution brings into the manner decision making is currently organized. As explained by Luoma (2016), it is of critical importance to structure the implementation in a format that fits with current routine practices at both the network and village bank level. Consequently, our first recommendation deals with the development of a structure allowing the implementation of our data-driven solution throughout the $\mathrm{MC}^{2}$ network that is based on (i) a research center on microfinance, (ii) working with extension staff from ADAF, (iii) creating support groups for village banks, and (iv) a flexible management of their commitment to performance.

The existence of a research center hosting analytical tools and built upon a small team of independent experts is considered as essential by Clark and Wiesenfeld (2017) to the deployment of an effective data-driven decision making solution. Scientists of the research center have as an objective to implement, maintain, and develop further current analytical tools. Not being part of the network staff, they can stay more objective regarding recommendations provided to the network. At the same time, at least part of the members of this team needs to have competences on microfinance, so as being able to connect their findings with concerns of the $\mathrm{MC}^{2}$ network. A research center on microfinance has been recently created at the University of Dschang in Cameroon. It gathers together scholars with an experience on microfinance management and scientists with competences on data analysis and modeling. Besides, the location within the university is also considered as a major advantage to identify students interested in an internship focusing on microfinance as well as on the implementation of DEA models, the provision of results to managers, or the development of current tools to address specific requests coming from the network. Besides, those students can be considered as potential candidates for positions in either the network or the research center. Otherwise, the responsible of the center will report on a regular basis to top managers of the $\mathrm{MC}^{2}$ network, with as an objective the provision of insights regarding the functioning of the network and suggestions on potential courses of action to be taken, especially in the context of a new decision on which top managers lack experience. In doing so, the person in charge of the research center will become an active participant of the boards of directors through the transfer of data-driven knowledge aiming to reduce the number of choices based only on intuition and instinct during the decision-making process. 
The second element of our recommendation concerns the way our results are transmitted to local managers. The best way appears to be by working with extension staff from ADAF that regularly visit village banks for monitoring their activity and advising them on main elements relative to their development. Extension staff of the network will receive regular training from the research center with as objectives the understanding of the functioning and usefulness of the results provided by the analytical solution and the development of a capacity to interpret results and to explain how to take actions based on these results to local managers of the network. They are not expected to know how models are built and worked out, but it is essential that they understand the value and limitations of the results (Liberatore and Luo, 2010). This latter point is of critical importance, since it is expected that they incorporate these results in their activity of extension services to help managers make decisions that could improve the performance of their village banks. Besides, these extension staff as users of the modeling tools will be responsible for providing data to the research center on a regular basis so that updated recommendations can be formulated.

For providing effective and relevant guidance to local managers, the DEA operating frontiers (DEA-OF) approach enables the stratification of village banks into operating frontiers and the definition of an actionable roadmap for improving the performance of each micro-bank. Besides, communication of results to managers is provided by means of scorecards built upon financial and non-financial indicators; translating DEA-OF results into ratios daily used by managers in order to give them concise and easy-to-use information. In doing so, no specific training of local managers is necessary, since they understand and already work with these indicators for monitoring and reporting on their activity. After identifying the strengths and weaknesses of each village bank, corrective measures have to be defined and implemented, when necessary. Done on a regular basis to monitor performance of village banks or to respond to a specific request of one or several village banks, the analytical solution presented herein can become a useful tool allowing the following up of the performance of the $\mathrm{MC}^{2}$ network. Indeed, potential deviations from their financial and social mission can be spotted at their very beginning. Regular updates and specific analyses upon request are planned to be carried out by the team located in the research center on microfinance. Updated results can be provided each time new data are available. In case of difficulty in the communication of the results to managers of village banks by extension staff, meeting in presence of a data analyst is highly recommended; especially if some adjustments imply to run again DEA models. Otherwise, a project of setting up support groups gathering together managers of village banks located on the same operating frontier i.e., sharing similar strengths and weaknesses with those identified as their role models by DEA-OF and extension staff as moderator has also been suggested. The objective of these support groups is the creation of a place for exchanging experience on performance improvements; helping them to share know-how and to gain information from village banks on a higher operating frontier that can be useful for doing better in areas identified as weaker. 
The last element of our recommendation deals with the commitment culture towards performance of the $\mathrm{MC}^{2}$ network. Organizations that are too data-driven can follow directions that can be counterproductive because of specific factors concerning their community or location not included in the DEA models. At the opposite, if organizations rely too heavily on intuition and instinct for making decisions, personal assumptions or preferences can be inadequate and can mislead decisions-making (Clark and Wiesenfeld, 2017). Thus, it is really important to adopt a flexible management of performance commitment (Ghemawat and del Sol, 1998). This means that adaptations over time of the courses of action as defined by our DEA-OF approach have to be considered when specific feedbacks are gained about elements that can impede the planned roadmap. This possibility of adapting to feedback is thought as highly valuable, especially in a context of deep poverty, where uncertainty and unexpected events often arise without warning. Accordingly, the step-by-step improvement paths provided by DEA-OF can be used to define a commitment towards performance in stages rather than a commitment all at once. Indeed, at each step of improvement paths, a flexible management of commitment involves a repositioning of the course of action based on new information obtained. At the extreme, it allows a provisional stopping in the development of village banks facing tough time in the implementation of their activity. As pointed out by Ghemawat and del Sol (1998), adaptation is all the difference between success and failure and thus is an important element to be taken into account when implementing data-driven recommendations. Our suggestion is that extension staff first present DEA results to local managers and adjust them in accordance with their current productive environment or postpone their implementation until unusual events making them impossible have been resolved (e.g. bad weather conditions, armed conflict, or important changes in the financial resources of the village bank). Then, an agreement between extension staff, local managers, and if necessary, the board of directors of village banks has to be obtained, so that actions aiming to increase performance can start.

\subsection{Feasibility test on field}

The second recommendation made to the $\mathrm{MC}^{2}$ network was to set up an experimentation before deploying the approach to all village banks. This test phase has as objective to verify the adequacy of our results using a sample of village banks voluntarily agreeing to follow up directions for performance improvement provided by our study. In suggesting so, our objective was an evaluation of the impact of our prescriptions on these $\mathrm{MC}^{2}$ and the difference with $\mathrm{MC}^{2}$ in a similar operating frontier not being part of this feasibility test.

Unfortunately, at the delivery of this recommendation, the $\mathrm{MC}^{2}$ network was dealing with the global financial crisis. The impact on the activity of the network was really huge. Indeed, at the time of our study, village banks of our sample had on average 1,974 members with a minimum of 282 and a maximum of 5,184. By the end of 2012, the number of client had increased for all MFIs, except of one 
of them for which the number of members had decreased by 29 (from 1,011 in 2009 to 982 in 2012). Otherwise, the minimal increase in clients was of 22 and the maximum increase of 1,060 members. Thus, the number of clients increased by $22 \%$ on average during the 2009-2012 period, with a range of variations from $-3 \%$ to $+77 \%$. Such increases were really important for some village banks. Besides, the number of women among the new members rose by $21 \%$ (82) on average, while the number of the poor increased by $43 \%$ (471) on average over the same timeframe. Thus, village banks of the $\mathrm{MC}^{2}$ network have served more poor clients after 2009 as a result of the global financial crisis.

As no possibility of feasibility test was expected before the recovery from the impacts of the global financial crisis, data collected over the period were used to evaluate how far our prescriptions were from what has been observed during the 2009-2012 period. Increases in outputs suggested by our DEA approach correspond to the first bar for each output on Figure 6, while other bars show increases actually observed over the 2010-2012 period. At the exception of the output women and members in year 2010, our prescriptions appear to be below what has been observed. Thus, they can be considered as achievable and actionable. These results provided to extension staff of the network will be used to illustrate the applicability of our suggestions aiming to foster performance of each village bank and of the $\mathrm{MC}^{2}$ network as a whole.

Insert Figure 6: Increase in outputs (\%) - 2009 base period

\subsection{Usefulness of the study for other MFIs and further developments}

The study described herein focuses on a network of village banks, i.e., an organization with different independent and non-profit business units sharing the same strategy, the same structure, and the same name. Main differences between the village banks are the community where they deploy their activities and the time in activity since their launching. Following Nelson (1991), we can assert that they are in much better position to imitate or learn from each other than from other organizational forms. Indeed, it is easier to replicate units from the same organization in another location than to comprehend and adopt strengths from other organizations. The DEA approach enables the identification of role models that can be emulated to improve performance and can support the development of a learning process. As village banks belong to the same network, it can be assumed that the know-how that is often tacit, in that those practicing a technique can do so with great facility, but they may not be able to transfer skill to others without demonstration and involvement, can be more easily transferred among them. Accordingly, DEA-OF can be used as a selection process to put together village banks that must share their know-how in order to render more explicit what is tacit and to facilitate the learning process towards a higher performance. 
Similarly, this approach can be replicated to any network of microfinance located either in Cameroon or elsewhere in the world. It can also be implemented to networks of for-profit business units, either independent or nor. However, the analysis framework describes herein cannot be replicated without adjustments to groups of MFIs working with different strategies and/or different organizational structures. Further developments are necessary in order to separate the effects that are specific to the management of the strategy selected by MFIs within a specific organizational structure from those that results from differences in their strategies and/or their organizational structures. In this context, it would be necessary to implement a DEA meta-frontier approach (O’Donnell et al., 2008) allowing us to provide similar prescriptions at the unit level as well as additional insights regarding the strategy and organizational structure of these MFIs.

Regarding further developments, it must be pointed out that the study was carried out using a sample for year 2009, i.e. just after the global financial crisis. As illustrated in Figure 6, the activity of the $\mathrm{MC}^{2}$ network was shaken. Nowadays, village banks are recovering from the shock, and a more normal activity resumes. As results provided in 2009 are no longer relevant, new prescriptions have been made based on more recent data, so as to be in accordance with the new productive environment left after the global financial crisis, and actions for disseminating new prescriptions are ongoing. Besides, an extension to this analytical solution has been developed that allows a performance analysis over time separating the impact of changes in the productive environment from changes in local management with the aim to isolate what is under and beyond control of managers of the $\mathrm{MC}^{2}$ network (Piot-Lepetit and Nzongang, 2017).

\section{Conclusion}

In this paper, we investigated the applicability of Data Envelopment Analysis (DEA), an OR technique, for assessing performance and identifying improvement paths in a multi-input and multioutput context. The case study focused on the village banks of the Mutuelles Communautaires de Croissance (or $\mathrm{MC}^{2}$ ) network in Cameroon. The analysis framework used is based three stages. First, efficiency measurements were assessed using the output-oriented DEA model defined by Piot-Lepetit and Nzongang (2014), while at the same time providing an identification of best-practices within the $\mathrm{MC}^{2}$ network as well as improvement goals for less efficient village banks. Second, a DEA operating frontiers (DEA-OF) model was designed and implemented. As some improvement goals provided by DEA involved important changes in the internal organization and management of $\mathrm{MC}^{2}$ far away from the best-practice frontier, DEA-OF has allowed the definition of a performance improvement path for each inefficient $\mathrm{MC}^{2}$, taking into account its current operating environment and providing realistic and achievable short-term goals until the long-term target identified by the conventional DEA approach. At the end of these two first stages, each $\mathrm{MC}^{2}$ got an efficiency diagnostic of its internal production process, and underperforming ones a multistep performance improvement path towards the best- 
practice frontier as well as model roles to emulate at each level. Thirdly, for effective guidance to managers of the network, the third stage of the framework dealt with the translation of DEA results into financial and non-financial indicators daily used by managers and organized through three different and interrelated scorecards. Finally, results were used to separate village banks into different operating frontiers and to identify those ready for the fourth phase of development of the $\mathrm{MC}^{2}$ network aiming to financially support community project fostering job creation in rural Cameroon.

Results indicated that $\mathrm{MC}^{2}$ are relatively efficient in the provision of financial (loans and savings) and social (number of clients, and number of the poor and women) outputs, since their efficiency is on average of 0.9 and none $\mathrm{MC}^{2}$ received a score below 0.6. Thus, the organization is able to behave efficiently, i.e., to provide its outputs while using at the most its scarce resources. However, efficiency improvements in all outputs suggested by the DEA approach were really difficult to implement in a single step for the least efficient $\mathrm{MC}^{2}$. The DEA-OF approach allowed us to characterize five operating frontiers within the $\mathrm{MC}^{2}$ network as well as improvement paths for the last four operating frontiers until the overall best-practice frontier. Each step of an improvement path implies an achievable and realistic increase in all outputs of less than $10 \%$, for a given level of inputs. The longest improvement path is for the youngest $\mathrm{MC}^{2}$ and contains 5 steps. Besides, the translation of DEA results into ratios has shown that $\mathrm{MC}^{2}$ on the last two operating frontiers focused more on their financial activity than on their social one; showing that these $\mathrm{MC}^{2}$, which are at the beginning of their activity, are more involved in the sustainable management of their financial services. However, as performance improves $\mathrm{MC}^{2}$ are able to reach more poor people, and as their client portfolio increase, the number of women becomes higher. Furthermore, services provided by these village banks are valuable for their members, and their cost decreases as performance increases. Finally, $\mathrm{MC}^{2}$ belonging to the second and third operating frontiers were identified as ready for the fourth phase of development of the $\mathrm{MC}^{2}$ network, while those on the efficiency frontier or first operating frontier where already involved in this new phase. The impact on their financial activity was highlighted and specific advisory support was suggested, so as to avoid a mission drift towards their social activity at the detriment of their financial sustainability. The last part of the paper describes the recommended structure and organization for implementing prescriptions provided throughout the network. It also described how an external event has delayed the complete deployment of recommendations; highlighting the challenge involved by a context of deep poverty when using data-driven decision making analytical support.

To conclude, the framework developed in this study allows a quantitative analysis that can provide a useful support to the decision-making process of a network of organizations in order to enable them to assess its performance, to identify top performers, to understand where the sources of superior performance can be found, and to suggest improvement paths. Furthermore, this analysis framework provides valuable information to microfinance institutions on how to efficiently use their scarce resources in accordance with their mission of poverty alleviation and their objectives of 
financial sustainability and outreach to the poor. Especially for the $\mathrm{MC}^{2}$ network in Cameroon, results and recommendations, provided by the study and described in this paper, are valuable for aligning their actions with their objectives and developing a flexible management of their commitment to performance towards their double bottom-line, so as to reach more poor people as well as to engage themselves in the granting of loans for larger projects promoting job creation in rural areas, where poverty remains important.

Besides, the analysis framework in three stages developed in this paper can be applied to other types of microfinance institutions in other countries. With the current debate on the trade-off between financial and social performance and the mission drift of some MFIs worldwide, a comprehensive assessment and enhancement of their performance become critically important for these microfinance institutions in order to achieve their social mission in a sustainable manner.

\section{Acknowledgments}

The authors would like to thank General Editor, Dr. Celso Ribeiro, Associate Editor, and two anonymous reviewers for their valuable comments and suggestions for improving the quality of the manuscript. We are also grateful to the participants at the ICORD 2017 - The International Conference on Operational Research for Development - and the IFORS 2017 - The International Federation of Operational Research Societies - for their constructive remarks on a previous version of this paper.

\section{References}

Basso, A., Funari, S., 2014. DEA models with a constant input for SRI mutual funds with an application to European and Swedish funds. International Transactions in Operational Research $21,979-1000$.

Basu, A., 2013. Five pillars of prescriptive analytics success. Analytics-magazine.org, March-April, 812.

Calabria, F.A., Camanho, A.S., Zanella, A., 2016. The use of composite indicators to evaluate the performance of hydropower plants. International Transactions in Operational Research. DOI: 10.1111/itor.12277.

CGAP - Consultative Group to Assist the Poorest, The World Bank Group, 2003, Microfinance Consensus Guidelines: Definitions of Selected Financial Terms, Ratios and Adjustments for Microfinance, $3^{\text {rd }}$ edition, Washington CD, USA.

Charnes, A., Cooper, W.W., Rhodes, E., 1978. Measuring the Efficiency of Decision Making Units, European Journal of Operational Research. 2, 429-444.

Chemak, F., Boussemart, J-P, Jacquet, F., 2010. Farming system performance and water use efficiency in the Tunisian semi-arid region: A data envelopment analysis approach. International Transactions in Operational Research 17, 3, 381-396 
Chen, Y-C, Chiu, Y-H, Chiu, C-J, 2017. The performance evaluation of banks considering risk: An application of undesirable relation network DEA. International Transactions in Operational Research. DOI: 10.1111/itor.12446.

Chiu, C-R, Chiu, Y-H, Fang, C-L, Pang, R-Z, 2014. The performance of commercial banks based on context-dependent range-adjusted model. International Transactions in Operational Research 21, 761-775.

Clark, T., Wiesenfeld, D., 2017. 3 things are holding back your analytics, and technology isn't one of them. Harvard Business Review, June.

Da Silva e Souza, G., Gonçalves Gomes, E., 2015. Improving agricultural economic efficiency in Brazil. International Transactions in Operational Research 22, 329-337.

Färe, R., Grosskopf, S., Lovel, C.A.K, 1985. The Measurement of Efficiency of Production. KluwerNijhoff Publishers.

Färe, R., Grosskopf, S., Lovell, C.A.K, 1994. Production Frontiers. Cambridge University Press, Cambridge.

Ghemawat, P., del Sol, P., 1998. Commitment versus Flexibility? California Management Review 40, 4, Summer, 26-42.

Ghiyasi, M., 2016. A DEA production technology and its usage for incorporation of collaboration in efficiency analysis: An axiomatic approach. International Transactions in Operational Research. DOI: 10.1111/itor.12325.

Gomez Junior, S.F, dos Santos Rubem, A.P., Soares de Mello J.C.C.B., Anguli Meza, L., 2016, Evaluation of Brazilian airlines non radial efficiencies and targets using an alternative DEA approach, International Transactions in Operational Research 23, 669-689.

Hermes, N., Lensink, R., 2007. The empirics of microfinance: What do we know? The Economic Journal 117, F1-F10.

Hsiao, B., Shu, L.C., Chou, F-Y, 2017. Assessing the efficiency of the accounting industry using multiactivity network DEA: Evidence from Taiwan. International Transactions in Operational Research. DOI: 10.1111/itor.12416.

Kounetas, K., Anastasiou, A., Mitropoulos, P., Mitropoulos, I., 2011. Department efficiency differences within a Greek university: An application of a DEA and Tobit analysis. International Transactions in Operational Research 18, 545-559.

Liberatore, M.J., Luo; W. 2010. The analytics movement: Implication for operations resreach. Interfaces 40, 4, July-August, 313-324.

Luoma, J., 2016. Model-based organizational decision-making: A behavioral lens. European Journal of Operational Research 249, 816-823.

Marques, R.C., Carvalho, P., 2013. Estimating the efficiency of Portuguese hospitals using an appropriate production technology. International Transactions in Operational Research 20, 233 249. 
Mees, M., Banda, J., 2001. The Mutuelles Communautaires de Croissance $\left(\mathrm{MC}^{2}\right)$ - Cameroon. SOSFaim, Zoom Microfinance 6, November.

Miamo Wendji, C., 2017. The millennium development goals progress measurement in Cameroon. In: Piot-Lepetit I. (Ed.), Cameroon in the 21st Century: Prospects and Challenges. Volume 2: Environment and People. Nova Science Publishers, New York. pp. 235-252.

Microrate, 2003. Performance indicators for microfinance institutions: Technical Guide, $3^{\text {rd }}$ ed. Morduch, J., 2000. The Microfinance Schism. World Development 28, 4, 617-629.

Moreno, P., Lozano, S., 2016. Super SBI dynamic network DEA appraoch to measuring efficiency in the provision of public services. International Transactions in Operational Research. DOI: 10.1111/itor.12257.

Nelson, R.R., 1991. Why do firms differ, and how does it matter? Strategic Management Journal 12, Winter, 61-74.

O’Donnell, C.J., Prasada Rao, D.S., Battese, G.E., 2008. Metafrontier frameworks for the study of firm-level efficiencies and technology ratios. Empirical Economics 34, 2, 231-255.

Piot-Lepetit, I., 2017. Cameroon in the 21st Century: Prospects and Challenges. Volume 1: Governance and Businesses. Nova Science Publishers, New York.

Piot-Lepetit, I., Nzongang, J., 2014. Sustainability, outreach to the poor, and best-practices of microfinance institutions within a network of village banks: The case of $\mathrm{MC}^{2}$ in Cameroon. European Journal of Operational Research 234, 1, 319-330

Piot-Lepetit, I., Nzongang, J., 2017. Assessing financial and social performance of microfinance institutions over time: The case of $\mathrm{MC}^{2}$ network in Cameroon. In: Piot-Lepetit I. (Ed.), Cameroon in the 21st Century: Prospects and Challenges. Volume 2: Environment and People. Nova Science Publishers, New York. pp. 253-287.

Sahoo, B.K., Kerstens, K., Tone, K., 2012. Returns to growth in a nonparametric DEA approach. International Transactions in Operational Research 19, 463-486.

Santin, D., 2014. Measuring the technical efficiency of football legends: Who were Real Madrid's alltime most efficient players? International Transactions in Operational Research 24, 439-451.

Schmenner, R. W., Swink, M. L., 1998. On theory in operations management. Journal of Operations Management 17, 97-113.

Schreiner, M., 2002. Aspects of outreach: A framework for discussion of the social benefits of microfinance. Journal of International Development 14, 591-603.

Seelos, C., Mair, J., 2005. Social entrepreneurship: Creating new business models to serve the poor. Business Horizons 48, 241-246.

Sherman, H. D., Zhu, J., 2013. Analyzing performance in service organizations. MIT Sloan Management Review, Summer. 
Shyu, J., Lieu, P-T, Chang, W., 2015. How the environment determines banking efficiency: A comprison of banking firms in Taiwan, Hong-Kong and Mainland China. International Transactions in Operational Research 22, 757-770.

Tran C.D.T-T., Villano, R.A., 2015. Measuring efficiency of Vietnamese public college: An application of the DEA-based dynamic network approach. International Transactions in Operational Research. DOI: 10.1111/itor.12212.

Watto, M., Mugera, A., 2016. Wheat farming system performance and irrigation efficiency in Pakistan: A bootstrapped metafrontier approach. International Transactions in Operational Research. DOI: 10.1111/itor.12314.

Woller, G.M., 2006. Evaluating MFIs' Social Performance: A Measurement Tool. microNOTE $\mathrm{n}^{\circ} 12$ and microREPORT $\mathrm{n}^{\circ} 35$.

Work Bank, 2016. Republic of Cameroon: Priorities for ending poverty and boosting shared prosperity. Systematic country diagnostic. Report $n^{\circ}$ 10398-CM.

Xia, M., Chen, J., Zeng, X-J, 2017. Data Envelopment Analysis based on team reasoning. International Transactions in Operational Research. DOI: 10.1111/itor.12447.

Yadav, V.K., Kumar, N., Ghosh, S., Singh, K., 2014. Indian thermal power plant challenges and remedies via application of modified data envelopment analysis. International Transactions in Operational Research 21, 955-977.

Yaron, J., 1994. What makes rural finance institutions successful? The World Bank Research Observer 9, 49-70.

Zeller, M., Meyer, R.L., 2002. The Triangle of Microfinance: Financial Sustainability, Outreach and Impact. IFPRI - International Food Policy Institute, The Johns Hopkins University Press, Baltimore, MD. 


\section{Tables}

Table 1

Descriptive statistics of DEA inputs and outputs (52 $\mathrm{MC}^{2}$ in 2009)

\begin{tabular}{lrrrrr}
\hline Variables & Units & Mean & Std-Dev & Minimum & Maximum \\
\hline Inputs & & & & & \\
Assets & FCFA 1,000 & 527,518 & 345,637 & 54,845 & $1,503,059$ \\
Equities & FCFA 1,000 & 135,649 & 75,486 & 24,901 & 375,334 \\
Personnel costs & FCFA 1,000 & 5,454 & 2,922 & 1,511 & 16,222 \\
Other operating costs & FCFA 1,000 & 13,977 & 9,965 & 2,376 & 46,006 \\
Outputs & & & & & \\
Loans & FCFA 1,000 & 176,458 & 130,698 & 19,420 & 61,353 \\
Savings & FCFA 1,000 & 395,288 & 293,904 & 24,987 & $1,299,370$ \\
Breadth: clients & number & 1,961 & 1,063 & 282 & 5,184 \\
Depth: the poor & number & 1,362 & 896 & 0 & 4,784 \\
Depth: women & number & 480 & 294 & 35 & 1,625 \\
\hline
\end{tabular}

Note: FCFA 1,000: around US\$ 2

Table 2

Selected indicators for translating DEA and DEA-OF results into scorecards

\begin{tabular}{lll}
\hline Triangle of microfinance & Outreach scorecard & Financial and non-financial indicators \\
\hline \multirow{2}{*}{ Financial sustainability } & \begin{tabular}{l} 
Length of outreach \\
\cline { 2 - 3 }
\end{tabular} & $\begin{array}{l}\text { Financial self-sufficiency ratio } \\
\text { Operational self-sufficiency ratio }\end{array}$ \\
\cline { 2 - 3 } Scope of outreach & No data available \\
\hline \multirow{3}{*}{ Outreach to the poor } & Breadth of outreach & Number of clients \\
& Depth of outreach & $\begin{array}{l}\text { Average loan size } \\
\text { Number of the poor } \\
\text { Number of women }\end{array}$ \\
\hline \multirow{4}{*}{ Welfare impact } & Worth to clients & $\begin{array}{l}\text { Provision expense ratio } \\
\text { Write-off ratio }\end{array}$ \\
& Cost to clients & $\begin{array}{l}\text { Yield on gross loan portfolio } \\
\text { Frequency of group meetings }\end{array}$ \\
\hline
\end{tabular}

Note: Specific definitions of these scorecards can be found in Schreiner (2002) and Zeller and Meyer (2002). 
Table 3

Improvement paths for inefficient $\mathrm{MC}^{2}$

\begin{tabular}{ccccc}
\hline Operating frontier & Improvement path & Model & Efficiency: mean & Inefficiency: \% \\
\hline \multirow{4}{*}{ OF5 } & OF5 to OF1 & DEA & 0.739 & 26.1 \\
\cline { 2 - 5 } & OF5 to OF4 & & 0.956 & 4.4 \\
& OF4 to OF3 & \multirow{2}{*}{ DEA-OF } & 0.911 & 8.9 \\
& OF3 to OF2 & & 0.952 & 4.8 \\
& OF2 to OF1 & & 0.919 & 8.1 \\
\hline \multirow{4}{*}{ OF4 } & OF4 to OF1 & DEA & 0.774 & 22.6 \\
& OF4 to OF3 & & 0.950 & 5.0 \\
& OF3 to OF2 & \multirow{2}{*}{ DEA-OF } & 0.889 & 11.1 \\
& OF2 to OF1 & & 0.936 & 6.4 \\
\hline \multirow{3}{*}{ OF3 } & OF3 to OF1 & DEA & 0.839 & 16.1 \\
& OF3 to OF2 & \multirow{2}{*}{ DEA-OF } & 0.930 & 7.0 \\
\hline OF2 & OF2 to OF1 & & 0.909 & 9.1 \\
\hline All inefficient $M C^{2}$ & OF2 to OF1 & DEA & 0.942 & 5.8 \\
\hline
\end{tabular}




\section{Figures}

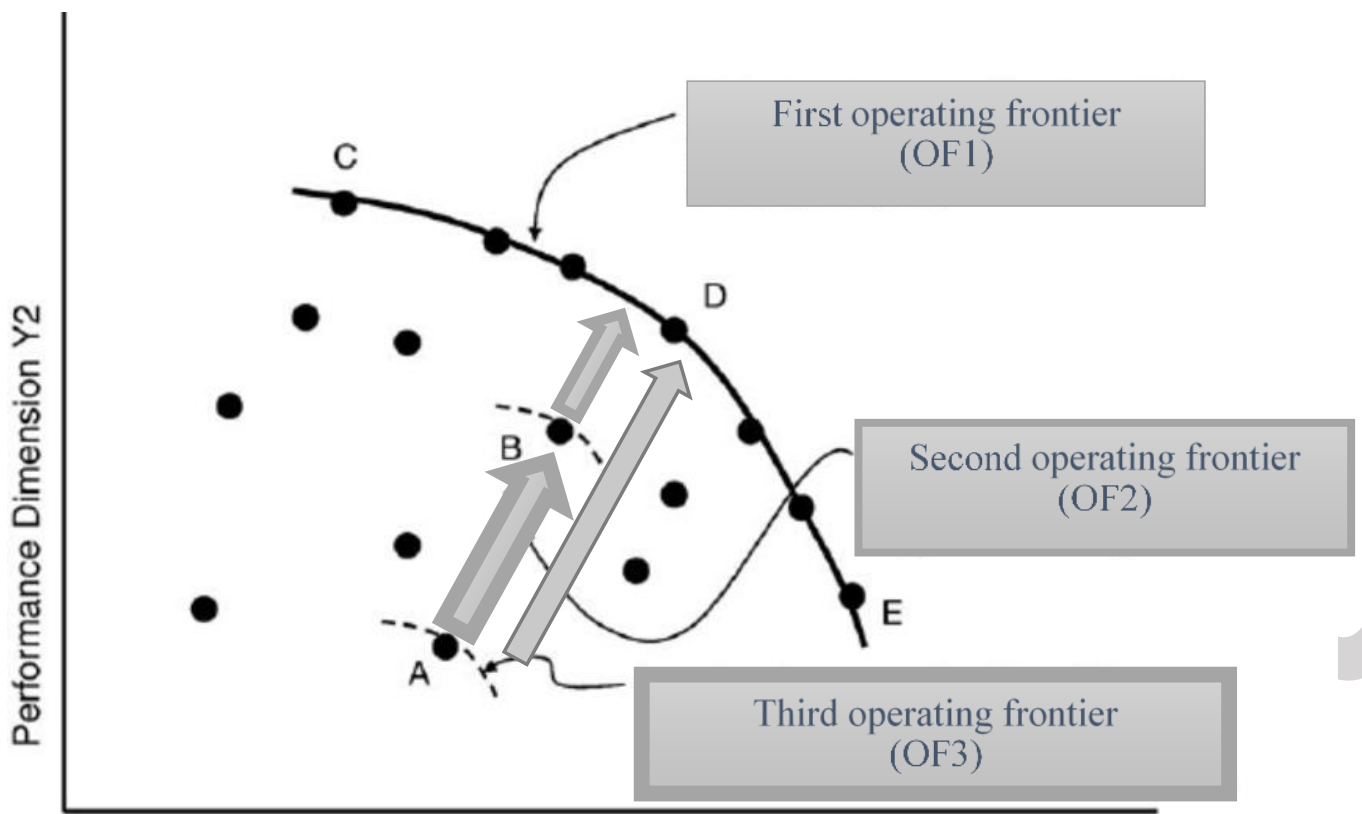

Performance Dimension Y1

Fig 1. The theory of performance frontier (Schmener and Swink, 1998)

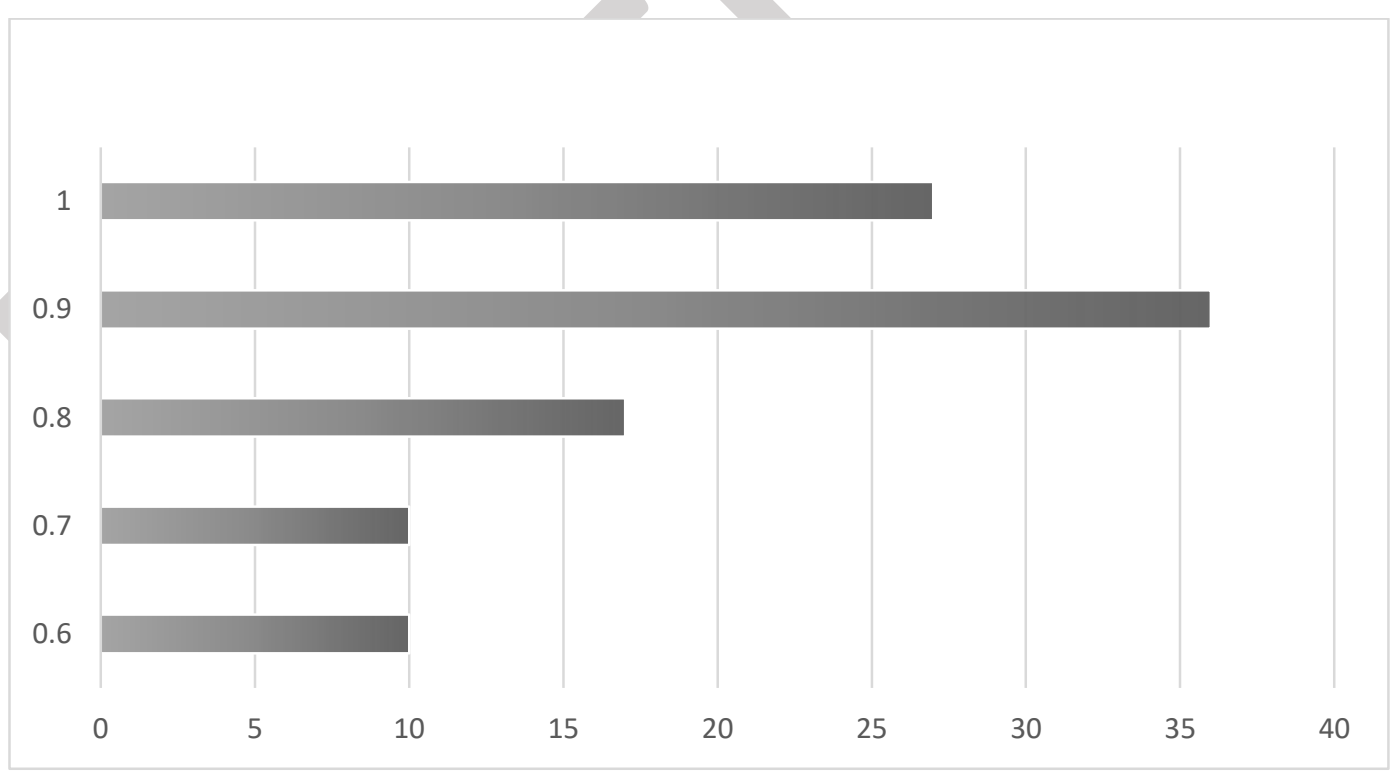

Fig. 2. Distribution of DEA efficiency scores (\%) 

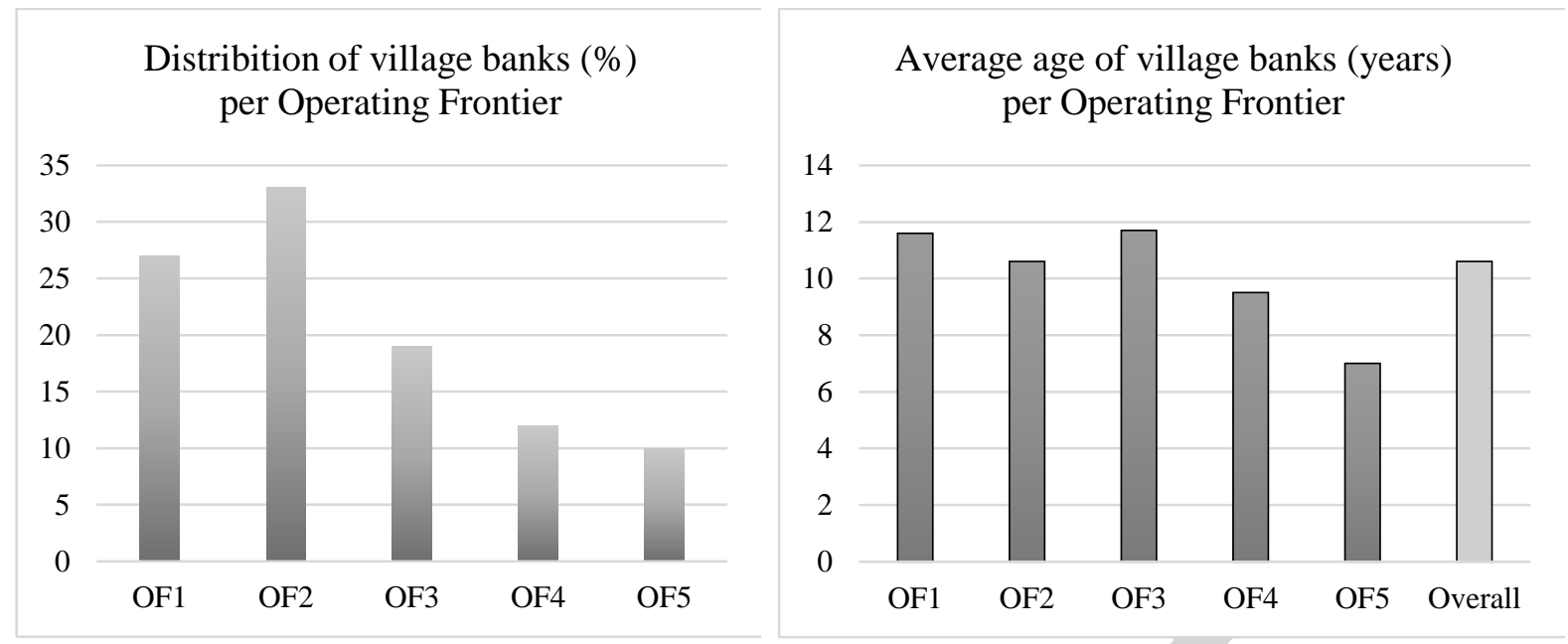

Note: OF: Operating Frontier

Fig. 3. Distribution and average age of village banks per operating frontier

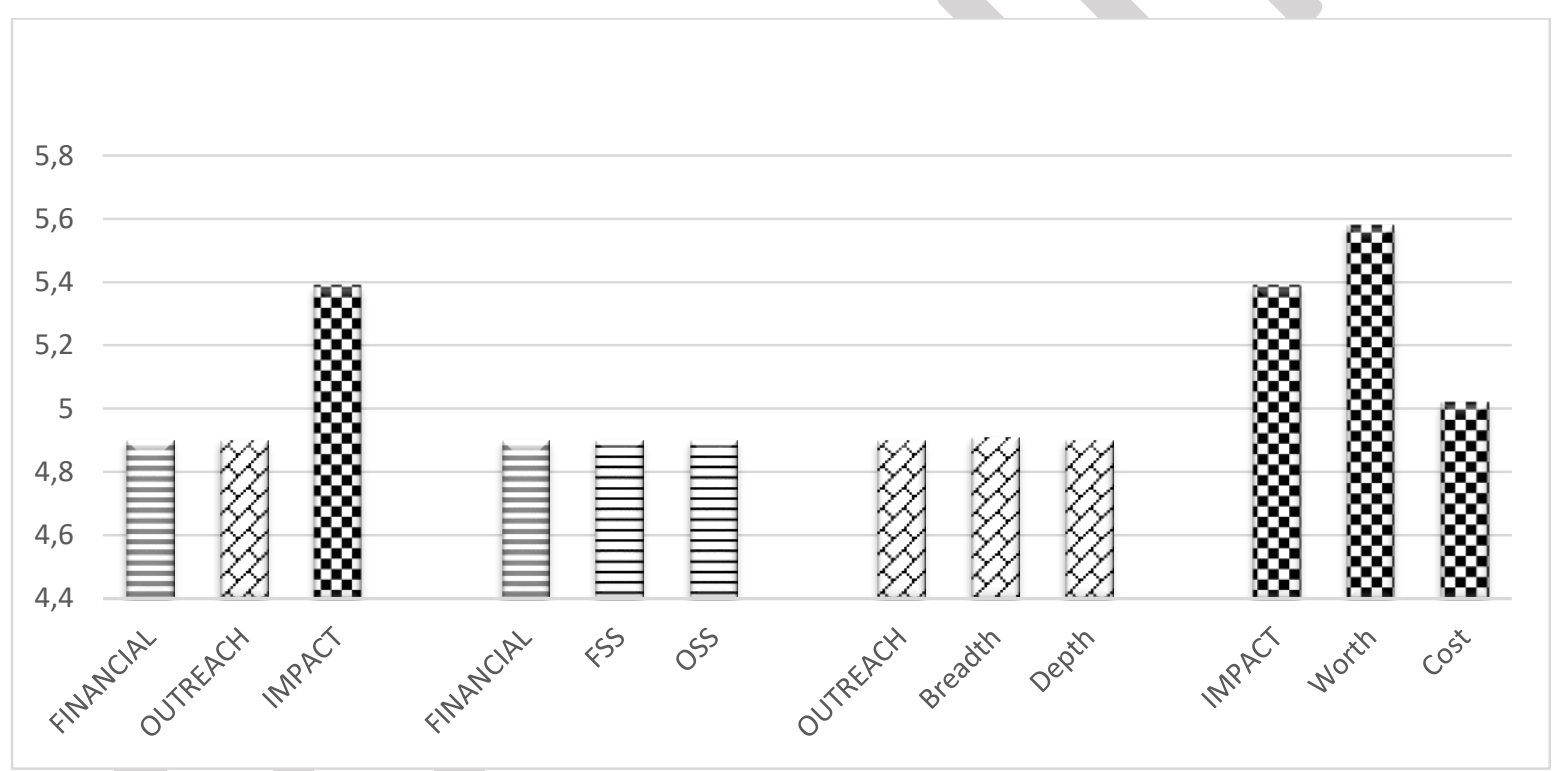

Notes: FSS - Financial self-sufficiency; OSS - Operational self-sufficiency

Fig. 4. Translation of DEA goals into scorecard 
Triangle of Microfinance per Operating Frontier
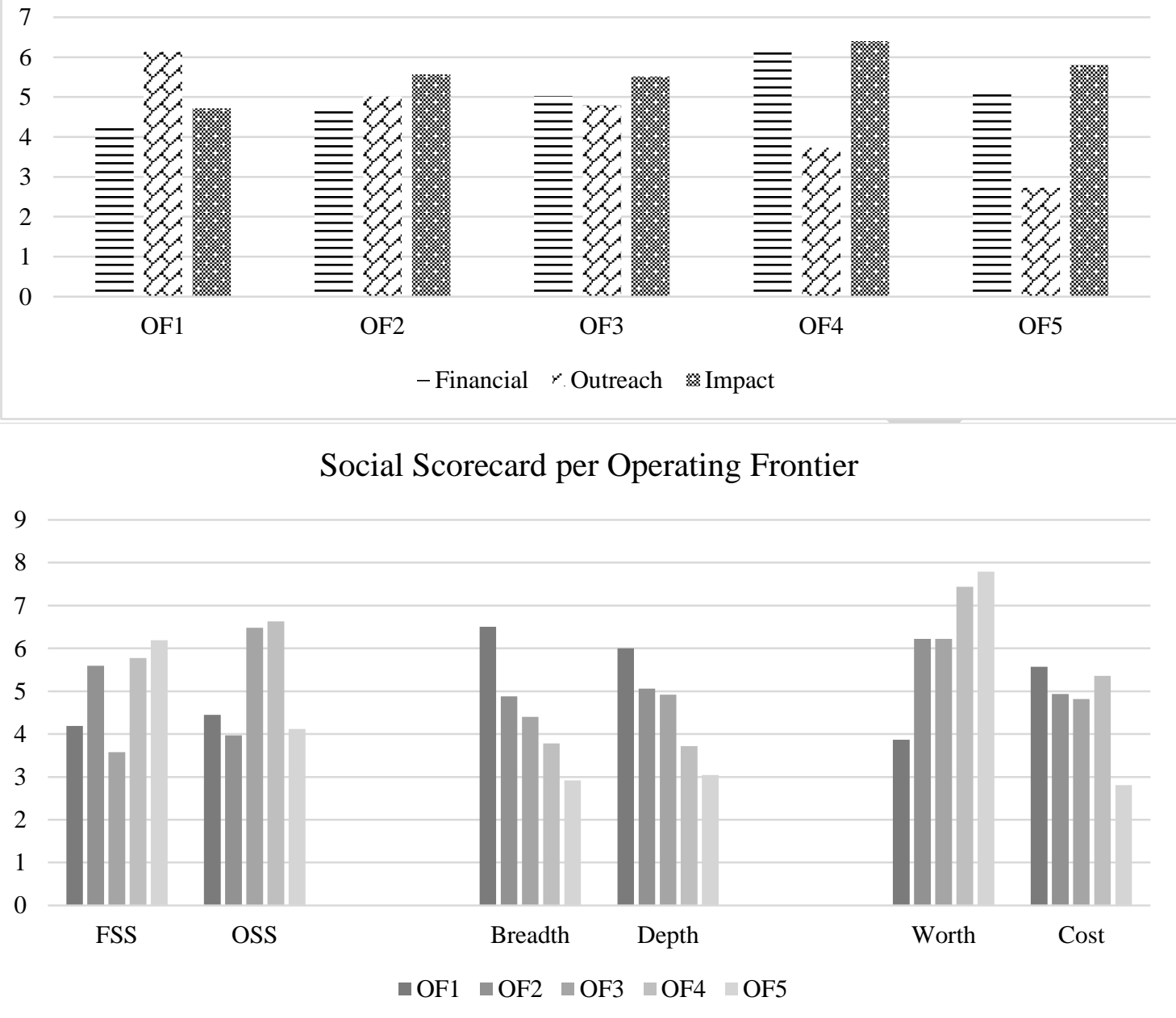

Notes: OF: Operating Frontier; FSS: Financial Self-Sufficiency; OSS: Operational SelfSufficiency

Fig. 5. Translation of DEA-OF goals into scorecards 


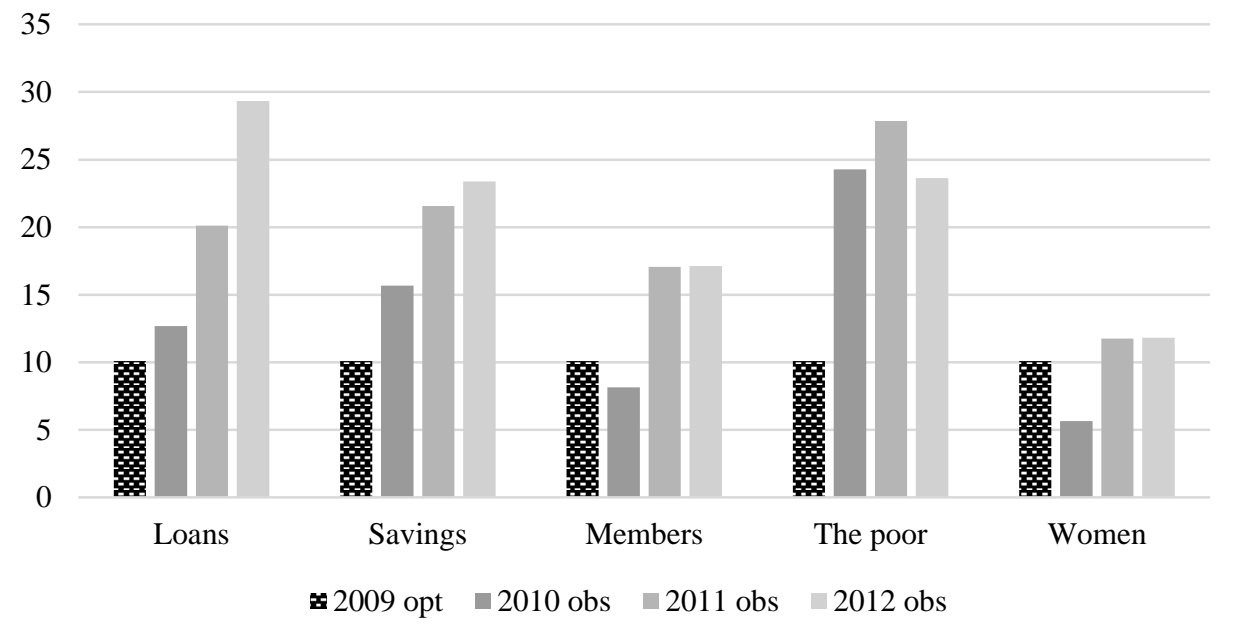

Fig. 6. Increase in outputs (\%) -2009 base period 